\title{
APOIO INSTITUCIONAL E A MOTIVAÇÃO DO ALUNO NA EDUCAÇÃO A DISTÂNCIA: CONTRADIÇÕES E CONTRIBUIÇÕES A APRENDIZAGEM
}

\author{
FLORIANÓPOLIS/SC MAIO/2018
}

\author{
Daniela K. Ramos - UFSC - dadaniela@gmail.com \\ Fabiana Lopes Ribeiro - UFSC - fabigor@gmail.com \\ Gleice Assunção da Silva - UFSC - gleiceprojetos@gmail.com \\ Bruna Santana Anastácio－UFSC - brunaanastacio@hotmail.com
}

Tipo: Investigação Científica (IC)

Natureza: Relatório Final de Pesquisa

Categoria: Pesquisa e Avaliação

Setor Educacional: EDUCAÇÃO SUPERIOR

\begin{abstract}
RESUMO
Este estudo aborda as contribuições e contradições do apoio institucional e da motivação para os alunos do curso de Extensão a Distância Formação Continuada em Conselhos Escolares. Para tanto, realizou-se um pesquisa exploratória quantitativa com uma amostra de 325 cursistas, por meio da aplicação de um questionário. As questões objetivas procuraram identificar aspectos como o nível de motivação, o apoio institucional recebido, a atuação profissional e o tempo dedicado aos estudos. Os resultados indicam que a maioria dos cursistas participou motivada do curso e parte deles indicou receber algum tipo de apoio de suas instituições. Todavia, esse apoio não pode ser associado significativamente à motivação e ao tempo dedicado aos estudos. Apenas o tipo de função exercida apresentou influência sobre a motivação. Todavia questões específicas referentes ao apoio institucional destacam sua importância, mesmo não tendo sida identificada associação com a motivação dos alunos, o que se revelou contraditório.
\end{abstract}

Palavras-chave: Educação a distância; Aprendizagem; Apoio Institucional; Motivação 


\section{INTRODUÇÃO}

As políticas governamentais de educação tem investido na Educação a distância (EAD) para ampliar o acesso a oportunidades de aprendizado, fomentar ações para atualização profissional, apoiar a melhoria da qualidade das estruturas educacionais existentes, nivelar as desigualdades entre grupos etários, direcionar campanhas educacionais para públicos-alvo específicos e atender as necessidade da maior parte dos profissionais que precisam conciliar o trabalho e a vida familiar (MOORE e KEARSLEY, 2008).

A EAD visa prioritariamente atender um público adulto, o qual optar pela modalidade ou não tem possibilidades de frequentar uma instituição de ensino convencional, presencial e que tem pouco tempo disponível para dedicar a seus estudos (BELLONI, 2008). Dessa forma, ao dedicar-se aos estudos gasta tempo e esforço que poderiam ser utilizados para satisfazer as exigências normais da vida adulta (MOORE; KEARSLEY, 2008).

Além de atender um público específico, esta modalidade de educação se relaciona à utilização de algum recurso tecnológico e didático para mediar a comunicação entre professores e alunos de modo a flexibilizar os espaços e tempos no ensino e aprendizagem por meio das TIC (SILVA; FIGUEIREDO, 2012).

Na flexibilização do tempo e espaço combinada com o uso das TIC, torna-se relevante a autonomia para gerenciar e organizar suas tarefas através dos cronogramas e interações com os professores formadores. Os hábitos e aptidões de estudo dos alunos determinam, em grande parte, o sucesso nas aulas online, e este é um fator que os alunos podem controlar (MOORE; KEARSLEY, 2008). Os alunos que planejam seu tempo de estudo e estabelecem horários para concluir o curso, tem maior possibilidade de obter sucesso na educação a distância (MOORE; KEARSLEY, 2008).

Nesse sentido, existem dois aspectos relacionados à questão do tempo de estudos na EAD como: a flexibilização do tempo como um fator importante para os respondentes (ABADI; REHFELDT, 2016) e também a questão de organização do tempo para realização dos estudos e execução das atividades (RAMOS, 2013).

Muitas vezes a inserção em cursos de EAD parte de necessidades vinculadas a atuação profissional. Nesse cenário as instituições podem contribuir para garantir melhores condições para o estudo e atualização, por meio da oferta de incentivos e o apoio institucional. Entretanto, sabe-se que está não é uma realidade para muitos do cursistas da EAD. Diante disso, tem-se como objetivo analisar as condições e o apoio institucional 
na formação a distância em serviço e verificar se é possível associar essas condições aos níveis de motivação e ao tempo dedicado aos estudos.

Segundo Moore e Kearsley (2008) alguns fatores podem contribuir para a aprendizagem do aluno à distância, como o reconhecimento da relevância do conteúdo, o nível de dificuldade do curso, o grau de apoio recebido, as tecnologias utilizadas, $s$ formas de acompanhamento e as interações sociais. Kuo et al. (2014) acrescenta, ainda, a esses fatores a autonomia, a auto-eficácia e auto-regulação da aprendizagem, como aspectos que contribuem fortemente na percepção de sucesso de um curso a distância.

Por outro lado, muitas questões podem ser responsáveis pela evasão e/ou percepção sobre o insucesso de uma formação à distância. A falta de tempo é a reclamação principal, o que fica evidente na pesquisa de Ramos (2013). Todavia, outros fatores, relacionados direta ou indiretamente com a falta de tempo apontada pelos alunos, carecem de atenção.

Para Almeida (2008), a falta de apoio no trabalho, os problemas familiares e os problemas de saúde podem contribuir com evasão na modalidade, principalmente, por conta das características do público atendido, o qual tem que conciliar os processos de formação com suas vidas profissionais e familiares.

Nesse sentido, Cislaghi e Luiz Filho (2009) também identificaram questões pessoais, responsáveis por gerar problemas para quem estuda à distância, bem como, necessidade de trabalhar, casamento, nascimento dos filhos, mudança de país ou localidade, problemas de saúde, falta de apoio no local de trabalho, ou mudanças no contexto socioeconômico geral.

De outro modo, destaca-se que o apoio institucional ou apoio no local de trabalho é uma temática pouco explorada nas pesquisas sobre os processos de formação continuada à distância. Apesar de aparecer como uma questão relevante para o insucesso em pesquisas como de Almeida (2008) e Cislagui e Luiz Filho (2009).

\section{METODOLOGIA}

O presente estudo tem caráter exploratório e abordagem quantitativa, com o intuito de compreender os processos de ensino e aprendizagem que ocorrem na modalidade à distância, destacando aspectos como o apoio institucional e a motivação, bem como suas contradições e contribuições a aprendizagem. O campo da pesquisa foi o curso de Extensão a Distância Formação Continuada em Conselhos Escolares, mais 
precisamente quatro ofertas semestrais do referido curso, ofertado pela Universidade Federal de Santa Catarina - UFSC, nos anos de 2013 e 2014. A amostra compôs-se por conveniência pela disponibilidade dos cursistas em responder ao instrumento, totalizando 325 participantes de uma população de 465 concluintes.

A coleta de dados foi realizada por meio da aplicação de um questionário on-line, o qual apresentava questões relacionadas ao perfil dos alunos, identificando comportamentos relacionados a sua forma de estudo, bem como os aspectos que contribuem para sua aprendizagem. Ainda, no questionário foram propostas algumas questões objetivas, dentre elas, nível de motivação, apoio institucional, atuação, tempo e local de estudo dedicados ao curso. A análise orientou-se pela estatística descritiva e fez-se, também, uso do teste qui-quadrado para analisar a diferença nas frequências poderia ser considerada significativa. Para a análise, os dados foram tabulados em planilhas eletrônicas e utilizou-se o software SPSS para análise estatística.

\section{RESULTADOS}

Os resultados apresentados destacam dois fatores avaliados pelos cursista no instrumento de avaliação do curso, um primeiro refere-se ao nível de motivação verificado pelo nível de concordância indicado para a afirmação: "Participo do curso motivado(a)" e o segundo aborda o apoio institucional recebido, o qual foi classificado pelos cursistas como adequado, parcialmente adequado ou inadequado. De modo geral, observou-se que a maioria dos cursistas tem um nível elevado de motivação para realizar o curso, pois $65,23 \%$ concordou plenamente que participava motivado do curso e $31,08 \%$ concordou com a afirmação, apenas $0,92 \%$ não concordou, nem discordou, $2,77 \%$ discordou e nenhum discordo plenamente.

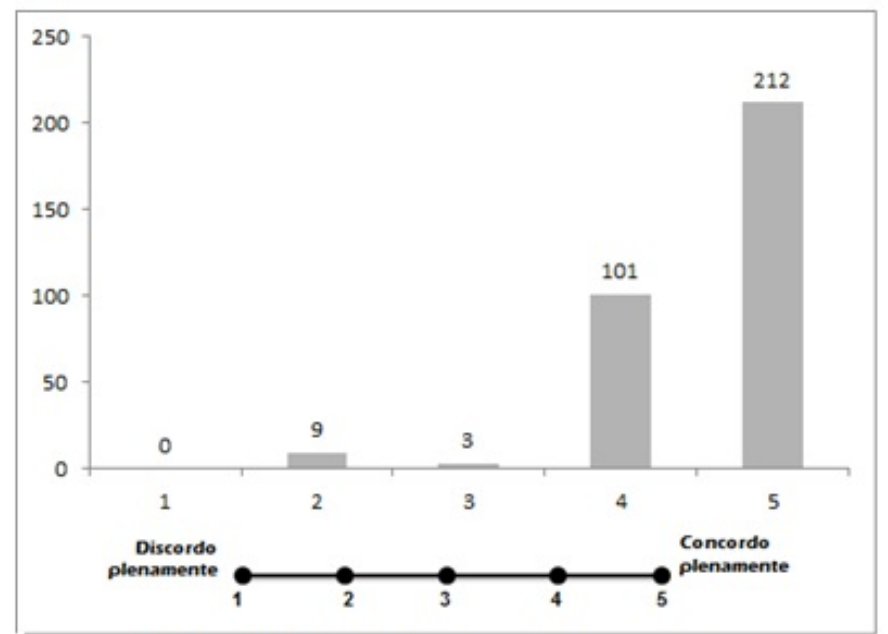

Gráfico 1. Nível de motivação dos cursistas 
No que se refere a avaliação do apoio institucional recebido $75,08 \%$ considerou adequado o apoio recebido, 20,62\% apreciou como parcialmente adequado e 4,31\% indicou como inadequado, conforme observa-se no gráfico 2.

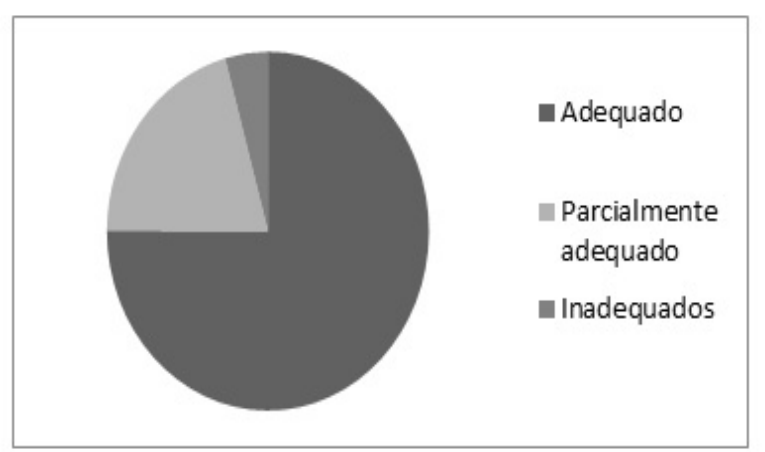

Gráfico 2. Avaliação do cursista sobre o apoio institucional recebido

O apoio institucional incluiu a possibilidade de dedicar horas da carga horária para realização do curso, fator que revelou que $39,38 \%$ dos cursista teve esse tipo de apoio. Outra forma avaliação foi o acompanhamento da instituição para realização do curso, o que poderia incluir a prestação de contas, auxílio para realização de coletas de dados solicitadas nas atividades ou orientações sobre os conteúdos abordados. Em relação ao acompanhamento $40,07 \%$ dos cursista considerou que foi acompanhado.

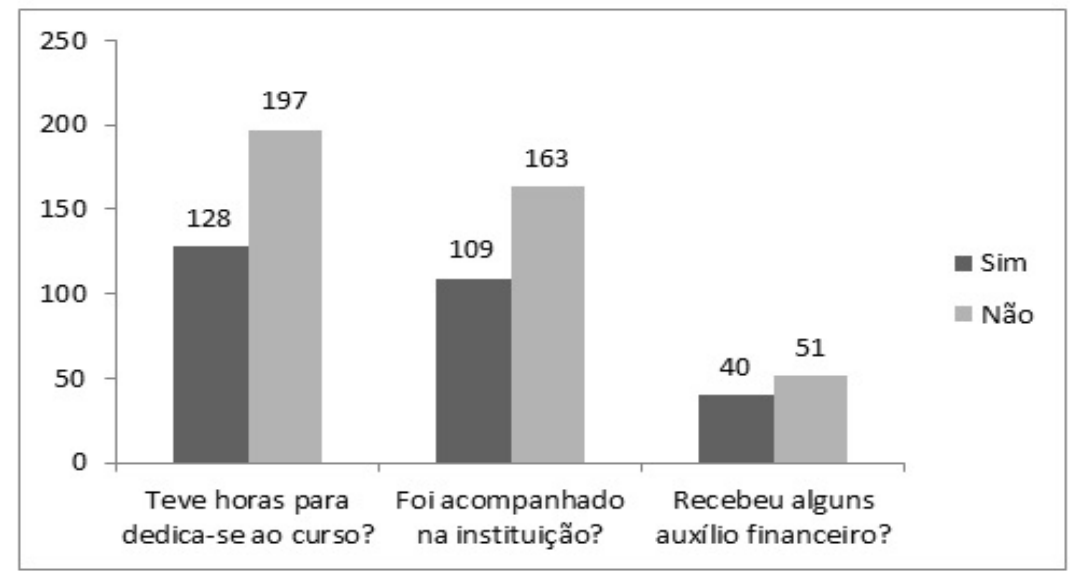

Gráfico 3. Tipo de apoio recebido institucionalmente.

Outro fator analisado referiu-se ao recebimento do auxílio financeiro, o qual esteve vinculado a participação no encontro presencial. Nesse contexto, apenas 14,7\% recebeu algum auxílio, sendo que 5,5\% recebeu auxílio total e 9,2\% parcial, 15,7\% não teve auxílio algum para participar do encontro e 66,5\% dos cursistas não participaram do encontro presencial, a qual se configurou como atividades não obrigatória de abertura do curso organizada na sede da Universidade.

O curso voltado para técnicos das secretarias de educação, incluindo diversos 
municípios, inclui cursistas com diferentes funções desempenhadas, a maior parte eram técnicos ou assistentes administrativos (29,54\%), seguidos por assistentes técnicos pedagógicos $(22,46)$ e outros $(19,38 \%)$, o que incluiu coordenadores pedagógicos, professores e auxiliares de sala, por exemplo.

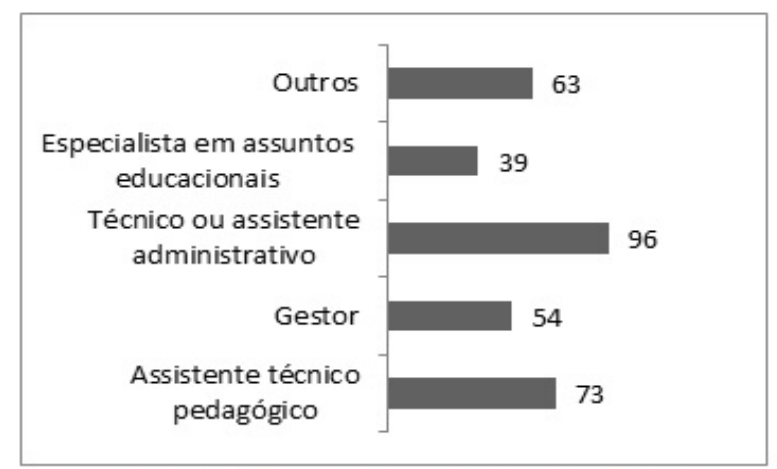

Gráfico 4. Função desempenhada no trabalho.

Ao questionar o tempo dedicado aos estudos durante a realização do curso, observouse que a maior parte dos cursistas dedica de 3 a 5 horas por semana, seguido por 1 a 2 horas, conforme pode-se observar no gráfico 5.

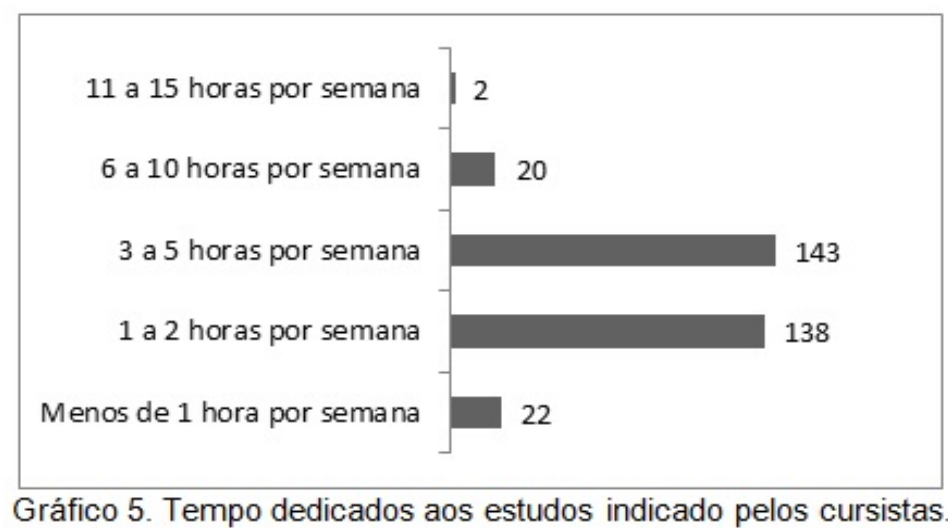

A maioria dos cursistas indica que estuda em casa $(n=211)$, o que corresponde a $65,53 \%$, já 33,23\% ( $n=107)$ informa que se dedicam a realização do curso na instituição em que atuam e apenas $1,2 \%(n=4)$ indicaram estudar em outro local.

Ao considerar-se o nível de motivação averiguou-se se o tipo de função exercida poderia ter alguma influencia sobre o nível de motivação. O cálculo do Qui-quadrado, para análise de associação entre o nível de motivação e o tipo de atuação do cursista, o qual resultou em $X^{2}=12,23$ ( $\left.g l=18 ; p>0,05\right)$, revelou independência entre essas variáveis. 


\begin{tabular}{|c|c|c|c|c|c|c|c|c|c|c|c|}
\hline & \multirow{2}{*}{\multicolumn{11}{|c|}{ Nivel de Motivação }} \\
\hline & & & & & & & & & & & \\
\hline & 1 & $\%$ & 2 & $\%$ & 3 & $\%$ & 4 & $\%$ & 5 & $\%$ & Total \\
\hline $\begin{array}{l}\text { Assistente técnico } \\
\text { pedagógico }\end{array}$ & 0 & 0 & 2 & 2,74 & 0 & 0,00 & 25 & 34,25 & 46 & 63,01 & 73 \\
\hline Gestor & 0 & 0 & 1 & 1,85 & 2 & 3,70 & 19 & 35,19 & 32 & 59,26 & 54 \\
\hline $\begin{array}{l}\text { Técnico ou assistente } \\
\text { administrativo }\end{array}$ & 0 & 0 & 2 & 2,08 & 1 & 1,04 & 29 & 30,21 & 64 & 66,67 & 96 \\
\hline $\begin{array}{l}\text { Especialista em } \\
\text { assuntos educacionais }\end{array}$ & 0 & 0 & 2 & 5,13 & 0 & 0,00 & 11 & 28,21 & 26 & 66,67 & 39 \\
\hline Outros & 0 & 0 & 2 & 3,17 & 0 & 0,00 & 17 & 26,98 & 44 & 69,84 & 63 \\
\hline Total & 0 & 0 & 9 & 2,77 & 3 & 0,92 & 101 & 31,08 & 212 & 65,23 & 325 \\
\hline
\end{tabular}

Tabela 1. Frequência do nível de motivação por tipo de função.

Outros fatores analisados de maneira cruzada referiram-se a relação entre o nível de motivação e avaliação do apoio institucional, o que revelou não haver associação, considerando o resultado para o teste qui-quadrado de Pearson, $X^{2}=7,90 \quad(g \mathrm{l}=6$; $\mathrm{p}>0,05)$.

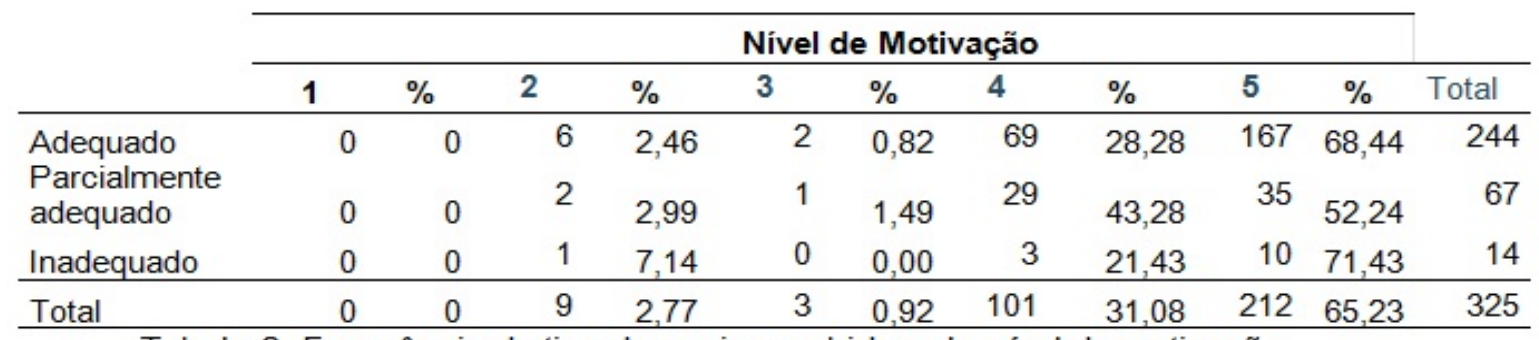

Tabela 2. Frequência do tipo de apoio recebido pelo nível de motivação.

Por fim, ao analisar-se a associação entre o apoio institucional e o tempo de estudo indicado pelos cursista, observa-se que não se pode estabelecer uma dependência entre as duas variáveis, pois obteve os seguintes resultados: $X^{2}=6,92(g l=8 ; p>0,05)$.

\begin{tabular}{|c|c|c|c|c|c|c|c|c|c|c|c|}
\hline & \multicolumn{10}{|c|}{ Tempo de Estudo } & \multirow{2}{*}{ Total } \\
\hline & 1 & & 2 & & 3 & & 4 & & 5 & & \\
\hline \multirow{2}{*}{$\begin{array}{l}\text { Adequado } \\
\text { Parcialmente } \\
\text { adequado }\end{array}$} & 16 & 6,56 & 106 & 43,44 & 103 & 42,21 & 18 & 7,38 & 1 & 0,41 & 244 \\
\hline & 6 & 8,96 & 27 & 40,30 & 31 & 46,27 & 2 & 2,99 & 1 & 1,49 & 67 \\
\hline Inadequado & 0 & 0,00 & 5 & 35,71 & 9 & 64,29 & 0 & 0,00 & 0 & 0,00 & 14 \\
\hline Total & 22 & 6,77 & 138 & 42,46 & 143 & 44,00 & 20 & 6,15 & 2 & 0,62 & 325 \\
\hline
\end{tabular}

Nota. 1 - Menos de 1 hora por semana; 2 - 1 a 2 horas por semana; 3 - 3 a 5 horas por semana; 4 - 6 a 10 horas por semana; 5 - 11 a 15 horas por semana; 6 - mais de 16 horas por semana.

Tabela 3. Frequência do tipo de apoio recebido pelo tempo de estudo.

\section{DISCUSSÃO}

Com relação ao tempo, a maioria dos respondentes (65,53\%) afirma que estuda em casa, retomando a questão apresentada por Moore e Kearsley (2008) que a EAD permite hábitos e aptidões de estudos que os alunos podem controlar. A pesquisa de 
Abadi e Rehfeldt (2016) ressalta a flexibilização do tempo para os estudos, como uma característica importante para os alunos da EAD, bem como salienta Moore e Kearsley (2008) afirmando que a conveniência e flexibilidade da educação a distância são vantagens para todos os alunos.

Como exemplo disso, Abadi e Rehfeldt (2016) trazem a discussão sobre uma resposta da participante da pesquisa: "Nesta modalidade eu consigo conciliar vida pessoal e acadêmica, uma vez que sou mãe, dona de casa, esposa e funcionária", percebendo como a "flexibilidade do tempo" contribuiu para o sucesso da aluna, uma vez que ela desempenhava quatro funções enquanto estudava, além de apontar que o perfil dos alunos EAD é o de quem trabalha e necessita de horários flexíveis para poder estudar. Nesse sentido, há possibilidade de que o ambiente que as pessoas interagem com seus materiais do curso e com seus instrutores, pode ser seu local de trabalho ou sua residência, uma sala de aula ou um centro de aprendizagem, um hotel ou um avião (MOORE; KEARSLEY, 2008).

Outro destaque relacionado ao fator tempo, é revelado na pesquisa de Ramos (2013), onde o tempo é sentido como as maiores dificuldades dos alunos em um curso EAD. Nesse contexto, o aluno precisa dispor e organizar o tempo, características que são fundamentais para que o aluno tenha sucesso em seu processo de aprendizagem a distância, além de que o tempo dedicado aos estudos precisa ser organizado considerando outras pessoas, as atividades e os prazos previstos (RAMOS, 2013).

Além disso, há o exercício da atividade profissional juntamente com os estudos, identificado em mais de $90 \%$ dos respondentes, que se soma a necessidade de dedicar tempo aos filhos (RAMOS, 2013). Essa condição associada ao recebimento de apoio nas instituições em que trabalhavam para cursarem a formação continuada a distância revela que muitos receberam benefícios como horas remuneradas para realizar a formação em serviço, acompanhamento da Instituição que atua e algum auxílio financeiro. Porém, essa questão revelou-se contraditória, pois ainda que $75,08 \%$ dos respondentes consideraram adequado o apoio recebido de suas instituições, somente 39,38\% tiveram carga horária em serviço para realização do curso, 40,07\% se sentiram acompanhados por suas instituições e $14,7 \%$ receberam algum auxílio financeiro para a participação do encontro presencial.

Todavia mais de $95 \%$ dos respondentes se disseram motivados a participarem do curso, e o apoio institucional não teve relação com essa percepção de motivação, conforme teste qui-quadrado. Indicando que, nesse caso, a autorregulação e autonomia foram mais relevantes para o aluno do que o apoio recebido pelo cursista em seu local de 
trabalho. Diante disso, destaca-se que a motivação pode ser associada à autorregulação, ou seja, pode influenciar sobre a capacidade do aprendente de compreender e controlar a sua aprendizagem, o que tende a aumentar a probabilidade de persistência ao enfrentar dificuldades (SCHUNK \& ZIMMERMAN, 1994).

Assim, reforça-se que aprender no local de trabalho ou em casa é um desafio, porque existem muitas distrações que devem ser evitadas, ou seja, os alunos devem "treinar a si mesmos", conscientemente, para adquirir hábitos de estudo disciplinados, determinando o melhor período e o local em que podem estudar, sendo no trabalho ou até mesmo em casa (MOORE; KEARSLEY, 2008).

\section{CONSIDERAÇÕES FINAIS}

Em face aos dados e discussões apresentados nesse artigo se reforça a importância do apoio institucional como forma de oferecer melhores condições para formação. Apesar de não identificar uma associação com a motivação e tempo dedicado aos estudos, não podemos ignorar que o apoio institucional para a formação continuada precisa ser reivindicado.

Reconhece-se que uma abordagem mais qualitativa, por meio de entrevistas, por exemplo, poderia aprofundar e auxiliar na melhor compreensão dos resultados. Aspectos relacionados à motivação intrínseca poderiam ser observados, pois justificariam o fato de que aspectos contextuais não exercerem influencia sobre ela e a dedicação aos estudos. Por fim, reforça-se que aspectos como a motivação, a autorregulação da aprendizagem e autonomia do aluno são importantes para o sucesso dos alunos que estudam a distância.

\section{REFERÊNCIAS}

ABADI, A. M; REHFELDT, Márcia Jussara Hepp. Autonomia para aprendizagem: uma relação entre o fracasso e o sucesso dos alunos da educação a distância. Revista Práxis Educativa. Ponta Grossa, v. 11, n. 2, p. 310-331, maio/ago, 2016.

ALMEIDA, O. C. S. Evasão em cursos a distância: análise dos motivos de desistência. In: 14 Congresso Internacional ABED de Educação a Distância. Santos-São Paulo, Brasil. $2008 . \quad$ Disponível em: http://www.abed.org.br/congresso2008/tc/552008112738PM.pdf Acesso em Maio de 2018. 
BELLONI, M. L. Educação a Distância. 5. Ed. São Paulo: Autores associados, 2009.

CISLAGHI, R., Luz Filho, S. S. Um framework para a promoção da permanência discente no ensino de graduação e um modelo de sistema de gestão do conhecimento para IES brasileiras. In. IX Colóquio Internacional sobre Gestão Universitária na América do Sul, Florianópolis, Santa Catarina, 2009. Disponível em: https://repositorio.ufsc.br/xmlui/handle/123456789/35844 Acesso em Maio de 2018.

$\mathrm{KUO}, \mathrm{Y}$. et al. Interaction, Internet self-efficacy, and self-regulated learning as predictors of student satisfaction in online education courses. The Internet And Higher Education, [s.I.], $\quad$ v. 20, p.35-50, jan. $2014 . \quad$ Disponível em:<http://dx.doi.org/10.1016/j.iheduc.2013.10.001>. Acesso em: Maio de 2018.

MOORE, M.; KEARSLEY, G. Educação a distancia: uma visão integrada. Cengage Learning. São Paulo, 2008.

RAMOS, D. K. Perfil dos estudantes de licenciatura a distância e aspectos que contribuem para aprendizagem. Revista Reflexão e Ação, Santa Cruz do Sul, v.21, n. esp., p.199-220, jul./dez, 2013.

SCHUNK, D. H.; ZIMMERMAN, B. J. Self-regulation of learning and performance: Issues and educational applications. Hillsdale, NJ: Lawrence Erlbaum Associates, 1994.

SILVA, C. G.; FIGUEIREDO, V. F. Ambiente virtual de aprendizagem: comunicação, interação e afetividade na EAD. Revista Aprendizagem em EAD, v. 1, n. 1, 2012. 